\title{
A Comparative Study of the Causes and Methods of Completed Suicide Referred to Legal Medicine Organization in Bushehr Province, South of Iran, 2006-2015
}

\author{
Alireza Raeisi ${ }^{1}$, Mahmood Montazeri ${ }^{2}$, Hiyam Hosseini ${ }^{3, *}$ \\ Specialist Internal Medicine, Chancellor of Bushehr University of Medical Sciences, Bushehr, Iran \\ Head of Legal Medicine Center of Bushehr, Bushehr, Iran \\ Toxicology, Legal Medicine Center of Bushehr, Bushehr, Iran \\ *Correspondence: hosseini_hayam@yahoo.com
}

\begin{abstract}
Background: Suicide is a major health problem. The aim of this study was a comparative study of the causes and methods of completed suicide referred to legal Medicine Organization in Bushehr Province during the years 2006- 2015. Methods: This consideration has been done as a retrospective cross-sectional study; the data were collected by the check list. After coordination to the medico legal 343 cases of completed suicide lead to death over a ten year period from 2006 to 2015 were extracted and the data were analyses by SPSS software. Results: The rate of completed suicide was 2.43 and 1.12 suicides per 100,000 people in male and female, respectively. The mean age were 29.25 and 27.61 years in male and female, respectively $\mathrm{p}>0.05$. A higher completed suicide rate was found among single people. The most common ways of a suicide among people who live in Bushehr were hanging out 184(53.6\%), self-Immolation 83(24.2\%) and firearms 37(10.8\%). Motive of suicide was psychological disorders, Physical disease, Conflict with family and substance abuse. 43(12.5\%) people smoking and 22(6.4\%) people were both smoking and opioid. During the ten year period of studied, throughout the all years that frequency of hanging out has been higher than others. Conclusion: Due to the high incidence of completed suicide in young people and unmarried individuals also hanging out in male and self-burning in females are prevalent. So determination of preventive measures appears to be necessary. Social factors such as psychological disorders and family conflicts have a noticeable role from .Bushehr people.
\end{abstract}

Keywords: completed suicide; hanging out; self-Immolation; Bushehr; Iran 


\section{Introduction}

Suicide, a social and mental phenomenon, is a major health problem in most countries so was the second leading cause for individuals between the ages of 15-20 years (1-3). Yet data relating to the role social factors play in the development of this condition are lacking within low- and middleincome countries (4). The official statistics of the World Health Organization (WHO), reported the rate of suicide (per 100,000 people) ranged from 0.6 to 35.1 (5). In Iran, statistics show a number of 5.7 and 3.1 suicides per 100,000 people in men and women in 2001, respectively (6). Countries with high rates of older adult suicide has included European Union countries, Canada, the U.S., and several Asian countries, including Japan, Singapore, and Taiwan The rate of suicide in Iran is lower than western countries but is in a higher level in Middle East countries $(6,7)$ Western provinces including Ilam, Kermanshah, and Hamedan had the highest rate of suicide in Iran, including 19.53, 13.74, and 10.64, respectively, per 100,000 people between 2006 and 2010 (8) Suicide methods vary across countries. The most common method of suicide in in many Asian countries, fifteen European countries, in many Western countries is suicide by hanging (9-11) and in developed countries are firearms, car exhaust and poisoning, whereas in developing countries, they are pesticide poisoning, hanging and self-immolation (12). In the United States, the most common method of suicide was firearm (13). The most common methods of suicide among people who live in Iran were hanging, Self-immolation, firearms and poisoning (14). Age, residence, job status, educational level and marital status were significantly associated with completed suicide (15). These factors may vary significantly for different countries due to distinctions within social and cultural constructs (16) which need to be considered in suicide prevention planning. social related factors affected to suicide among Iranian population family conflict, marital problems, economic constrains and educational failures were the most frequent cause of attempted suicide (17). There is no information of comparative study of the causes and methods of completed suicide in Bushehr province.

\section{Methods}

This Ten-year population-based survey was conducted in Bushehr Province, the South of Iran, in 2015. The data on completed suicide was collected for ten successive years from 21 March 2006 to 20 March 2015 suicide, the data were compared with and adapted by information on suicide recoded 
by the Center of Province Forensic Medicine, which is compatible with the International Classification of Diseases Revision 10 (ICD-10) ${ }^{1}$ and the occupation status coding and classification with NS-SEC ${ }^{2}$. In analytical and cross sectional study pre conducted forms of suicide was engaged to register data, crude and specific completed suicides rates was computed along with other demographic variables such as age, gender, occupation, education, marital status, and other variables related to completed suicide, which included physical and mental illness, suicide method and the result of suicide. In order to maintain confidentiality, the individual's name, address, and phone number were not used. After collecting and coding the data, they were entered into SPSS software (version 19, SPSS Inc., Chicago, IL, USA) for analysis and calculation of the frequency of the most common methods of suicide in Bushehr province. It should be noted that due to the reduced frequency of some methods of suicide, the most common methods of suicide were examined. The most common methods of suicide (hanging, self-immolation and firearms) was generally determined by the Chi square Test with a significance level of $<0.05$ and The compared mean of age in different gender with Independent-Samples $T$ Test with a significance level of $<0.05$. The compared frequency motive of completed suicide and age was by One-Way ANOVA Test with a significance level of $<$ 0.05 .

\section{Results}

Table 1 demonstrates among 343 suicide death, 235(68.5\%) cases were male and 108(31.5\%) cases were female. The majority of 220(64.2\%) people were under 30 years old and 46(13.4\%) were more than 40 years old. The subjects were between ages 13 to 87 years old and the mean age was 28.73 years old. No statistically significant differences were observed for mean of age in different gender $\mathrm{P}$ value $=0.354$. Completed suicide in single subjects in comparison to married subjects was higher (50.7\% and, $46.1 \%$ respectively). But higher completed suicide rate was found among married people who were female. Among different educational levels in both of them (female \& male), completed suicide was higher in Guidance graduated subjects (34.7\%). On the other hand, the lowest observed rate was in university educational levels (6.4\%). The most common history of Addiction were smoking 43(12.5\%) and opioid 10(2.9\%) and both of them (smoking and opioid) 22(6.4\%) (Table1).

\footnotetext{
1 International Classification of Diseases - Tenth Revision

2 National statistics socio - economic Classification
} 
The most common ways of a suicide among people who live in Bushehr were hanging out 184(53.6), self-Immolation $83(24.2 \%$ ) and firearms 37(10.8) (Table2). The overall trend of Suicide has been increase during the 2006-2015(Table 2). Reason of suicide in 230 cases (67\%) was unknown, psychological disorders 76(22.1\%), Physical disease $16(4.7 \%)$ and family conflict $15(4.3 \%)$, substance abuse 6(1.7\%) (Table2).

Figure 1: Distribution plot of completed suicide methods, stratified by Gender

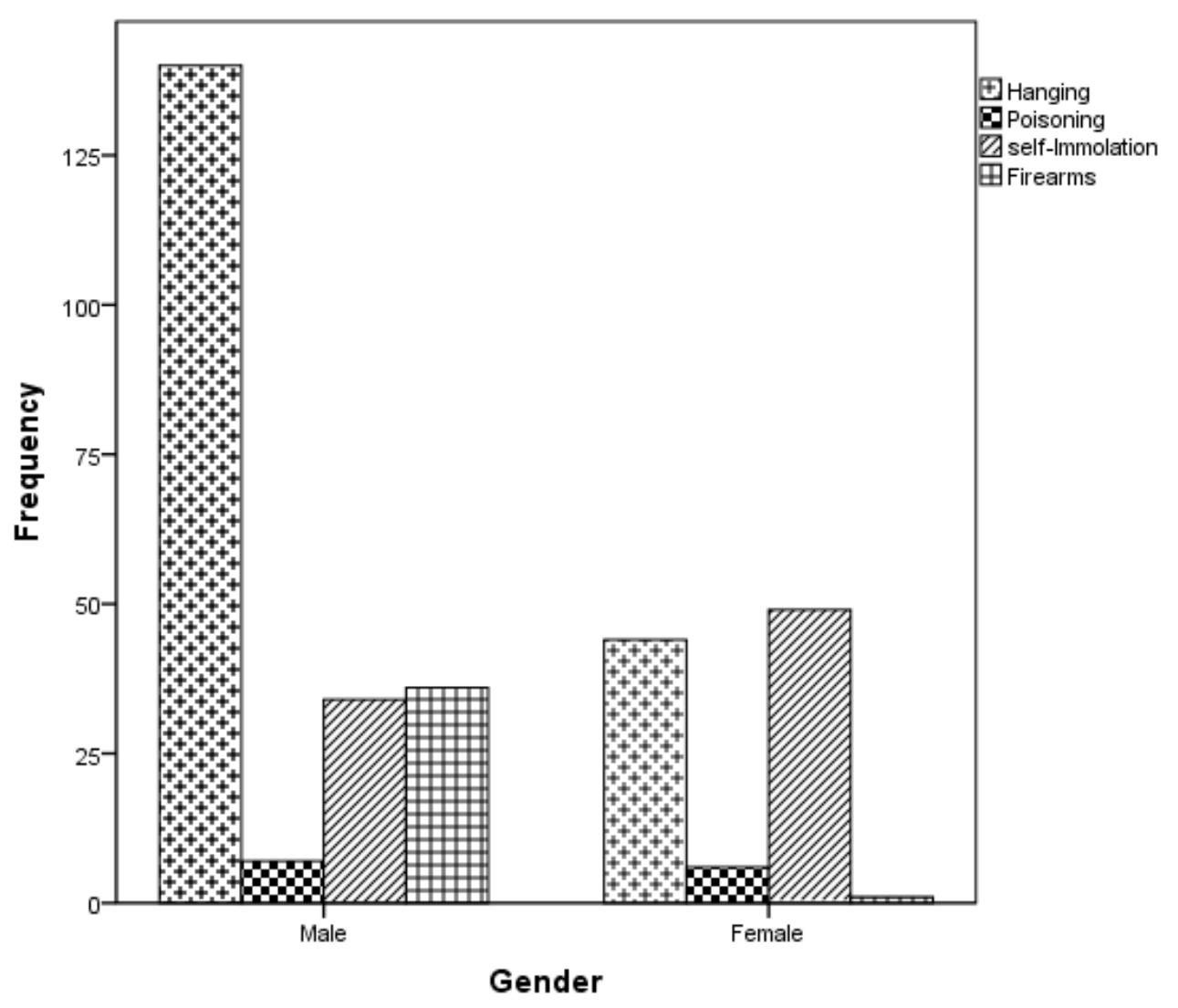


Figure 2: Distribution plot of reason of completed suicide, stratified by age

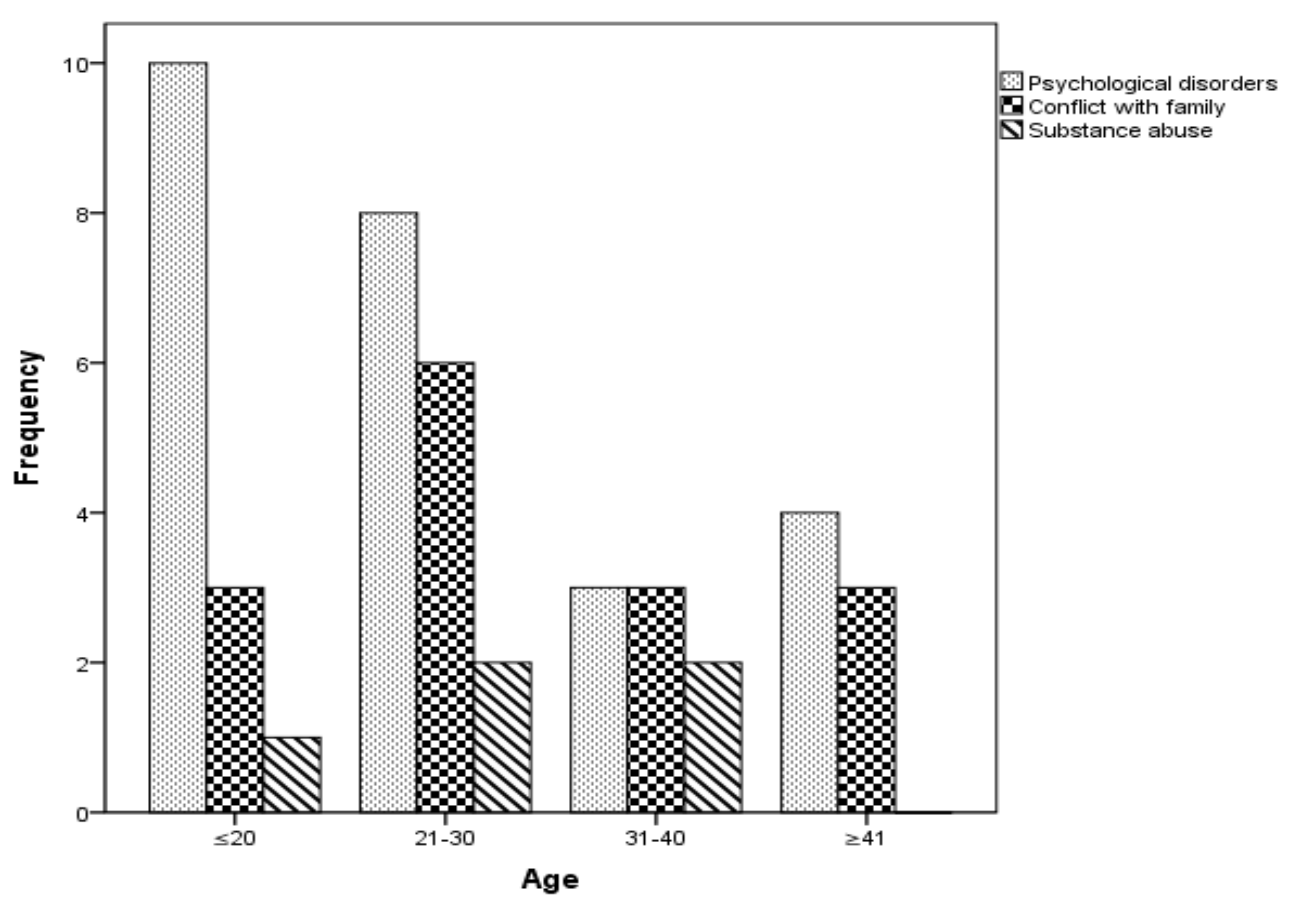

Figure 3: Method of completed suicide rate in different ages by year

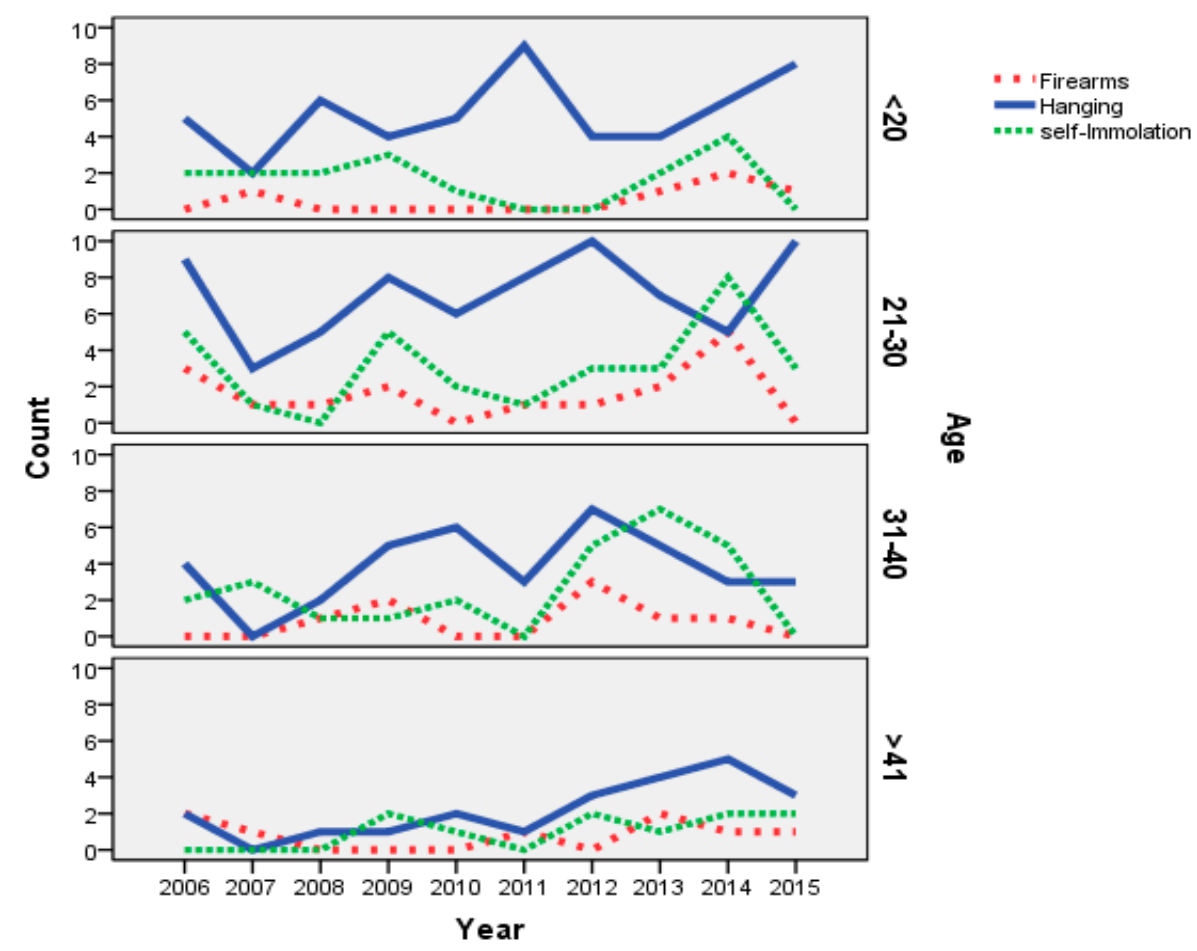


Table 1: The comparison of demographic in cases

\begin{tabular}{|c|c|c|c|c|}
\hline Variables & Female & Male & Total & P value \\
\hline $\begin{array}{c}\text { Gender } \\
\text { Female } \\
\text { Male }\end{array}$ & $108(31.5)$ & $235(68.5)$ & $343(100 \%)$ & 0.001 \\
\hline $\begin{array}{l}\text { Age group(year) } \\
\leq 20 \\
20-30 \\
31-40 \\
\geq 40\end{array}$ & $\begin{array}{l}29(26.9) \\
43(39.8) \\
25(23.1) \\
11(16.2)\end{array}$ & $\begin{array}{l}58(24.7) \\
90(38.3) \\
52(22.1) \\
35(14.9)\end{array}$ & $\begin{array}{l}87(25.4) \\
133(38.8) \\
77(22.4) \\
46(13.4) \\
\end{array}$ & 0.001 \\
\hline $\begin{array}{l}\text { Marital status } \\
\text { Single } \\
\text { Married } \\
\text { Others } \\
\end{array}$ & $\begin{array}{l}42(38.9) \\
59(54.6) \\
9(6.5)\end{array}$ & $\begin{array}{l}132(56.2) \\
99(42.1) \\
4(1.7)\end{array}$ & $\begin{array}{l}174(50.7) \\
158(46.1) \\
11(3.2)\end{array}$ & 0.0001 \\
\hline $\begin{array}{l}\text { Educational level } \\
\text { Illiterate } \\
\text { Primary school } \\
\text { Guidance } \\
\text { High school } \\
\text { Diploma } \\
\text { University }\end{array}$ & $\begin{array}{l}12(11.1) \\
31(28.7) \\
29(26.9) \\
13(12.0) \\
19(17.6) \\
4(3.7)\end{array}$ & $\begin{array}{l}17(7.2) \\
39(16.6) \\
90(38.3) \\
32(13.6) \\
39(16.6) \\
18(7.7)\end{array}$ & $\begin{array}{l}29(8.5) \\
70(20.4) \\
119(34.7) \\
45(13.1) \\
58(16.9) \\
22(6.4)\end{array}$ & 0.0001 \\
\hline $\begin{array}{l}\text { Occupation } \\
\text { School/College students } \\
\text { Unemployment } \\
\text { Housewives } \\
\text { Staff } \\
\text { Employed } \\
\text { people/Employees } \\
\text { Self-employed people } \\
\text { Military people } \\
\text { Others }\end{array}$ & $\begin{array}{l}12(11.1) \\
0 \\
91(84.4) \\
1(0.9) \\
1(0.9) \\
1(0.9) \\
0 \\
2(1.9)\end{array}$ & $\begin{array}{l}23(9.8) \\
51(14.3) \\
0 \\
7(3) \\
58(24.7) \\
46(19.6) \\
23(9.8) \\
27(11.5)\end{array}$ & $\begin{array}{l}35(10.2) \\
51(14.3) \\
91(84.4) \\
8(2.3) \\
59(17.2) \\
47(13.7) \\
24(7.0) \\
28(8.2)\end{array}$ & 0.0001 \\
\hline $\begin{array}{l}\text { Addiction } \\
\text { Smoking(A) } \\
\text { Opioid(B) } \\
\text { Alcohol(C) } \\
\text { Ecstasy(D) } \\
\text { A\&B } \\
\text { B\&C or B\&D } \\
\text { Unknown }\end{array}$ & $\begin{array}{l}1(0.9) \\
1(0.9) \\
1(0.9) \\
3(2.8) \\
1(0.9) \\
0 \\
101(93.5)\end{array}$ & $\begin{array}{l}42(17.9) \\
9(3.8) \\
2(0.9) \\
1(0.4) \\
19(8.1) \\
7(3.0) \\
155(66)\end{array}$ & $\begin{array}{l}43(12.5) \\
10(2.9) \\
2(0.6) \\
2(0.6) \\
22(6.4) \\
8(2.3) \\
256(74.6)\end{array}$ & 0.522 \\
\hline
\end{tabular}

Table 2: The frequency rate of method and reason completed suicide in different gender

\begin{tabular}{|l|l|l|l|l|}
\hline Factors & Female & Man & Total & P value \\
\hline Method of Suicide & & & & \\
Hanging & $44(40.7)$ & $140(59.6)$ & $184(53.6)$ & \\
Poisoning & $6(5.6)$ & $7(3.0)$ & $13(3.8)$ & \\
Drug overdose & $3(2.8)$ & $4(1.7)$ & $7(2.0)$ & 0.001 \\
Self-Immolation & $49(45.4)$ & $34(14.5)$ & $83(24.2)$ & \\
Firearms & $1(0.9)$ & $36(15.3)$ & $37(10.8)$ & \\
Falling from Height & $2(1.9)$ & $5(2.1)$ & $7(0.2)$ & \\
Others & $3(2.8)$ & $9(3.8)$ & $12(3.5)$ & \\
\hline Reason of Suicide & & & & 0.0001 \\
Psychological disorders & $30(27.8)$ & $46(19.6)$ & $76(22.1)$ & \\
Physical disease & $9(8.4)$ & $7(3.0)$ & $16(4.7)$ & \\
Conflict with family & $4(3.7)$ & $11(4.7)$ & $15(4.3)$ & \\
Substance abuse & $1(0.9)$ & $5(2.1)$ & $6(1.7)$ & \\
Unknown & $64(59.2)$ & $166(70.6)$ & $230(67.0)$ & \\
\hline
\end{tabular}


Table 3: Frequency and Incidence rate of completed suicide per 100,000 and by year.

\begin{tabular}{|c|c|c|c|c|c|}
\hline \multirow[t]{2}{*}{ Year } & \multicolumn{2}{|c|}{$\begin{array}{l}\text { Incidence rate of completed } \\
\text { suicide per } 100,000\end{array}$} & \multicolumn{2}{|c|}{ Frequency } & \multirow[t]{2}{*}{ Total } \\
\hline & Male & Female & Male & Female & \\
\hline 2006 & 2.7 & 1.13 & $24(10.2)$ & $10(9.3)$ & $34(9.9)$ \\
\hline 2007 & 1.13 & 0.68 & $10(4.3)$ & $6(5.6)$ & $16(4.7)$ \\
\hline 2008 & 2.14 & 0.56 & $19(8.1)$ & $5(4.6)$ & $24(7.0)$ \\
\hline 2009 & 2.5 & 1.47 & $22(9.4)$ & $13(12.6)$ & $35(10.2)$ \\
\hline 2010 & 2.7 & 1.47 & $24(10.2)$ & $13(12.0)$ & $37(10.8)$ \\
\hline 2011 & 2.22 & 0.77 & $23(9.8)$ & $8(7.4)$ & $31(9.0)$ \\
\hline 2012 & 3.3 & 0.77 & $34(14.5)$ & $8(7.4)$ & $42(12.2)$ \\
\hline 2013 & 2.7 & 1.25 & $28(11.9)$ & $13(12.0)$ & $41(12.0)$ \\
\hline 2014 & 2.3 & 0.96 & $27(11.5)$ & $22(20.4)$ & $49(14.3)$ \\
\hline 2015 & 2.6 & 2.1 & $24(10.2)$ & $10(9.3)$ & $34(9.9)$ \\
\hline Total & 2.43 & 1.12 & $235(68.5)$ & $108(31.5)$ & $343(100.0)$ \\
\hline$P$ value & \multicolumn{2}{|c|}{0.0001} & \multicolumn{3}{|c|}{0.0331} \\
\hline
\end{tabular}

\section{Discussion}

In Iran, statistics show a number of 5.7 and 3.1 suicides per 100,000 people in men and women in 2001, respectively (18) The estimated global mortality of suicide is 14.5 deaths per 100,000 people per year, which equates to one million deaths per year (19) but in Bushehr province, this survey show a number of 2.43 and 1.12 suicides per 100,000 people in men and woman during 20062015(Table3). Western provinces including Ilam, Kermanshah, and Hamedan had the highest rate of suicide in Iran; including 20, 14, and 10, respectively, per 100,000 people between 2006 and 2010(8, 20). Incidence of suicide in the province for men and women are lower than that was observed in the country, such as other deprived regions of the country. The most high risk groups for complete suicide were primary school housewife and Self-employed men with guidance education. The risk of completed suicide was higher among housewives, employed people. The lower education level was the higher the risk of completed suicide. In complete suicides almost happens under age 30 years in women married and in single men. Our analysis by method chosen to achieve death showed that the most frequently used was hanging, representing 53.6\% of the suicide rate during 2006-2015(Figure3). Different gender who committed suicide in Bushehr during 2006-2015 chooses a violent method. Hanging was the majority of violent methods among males and self-immolation was common method in females (Figure1). The most high risk groups for complete suicide were males with addiction history. The common reason of completed suicide in all ages was psychological disorders, physical disease and conflict with family (Figure2). Suicide is a multi-factorial problem with socio-related factors interacting reciprocally amongst each other with a great deal of overlap between these variables. The individual and environmental factors contribute to suicide vary substantially across 
countries and regions(20). In this study, the highest suicides rates in Bushehr population are observed among people under 30 years in different gender. Suicide risk decreases with age. In Bushehr, the highest suicide rate is observed in the group of 21-30 years of age. Despite its limitations, the current study may have a number of implications for health care policy. First, the most common risk factors for suicide were identified in the target population. Second, the effects of several demographic risk factors on completed suicide and deaths due to suicide were measured quantitatively. These findings may help policymakers who plan preventive program to reduce suicide rate and its associated predisposing factors. These evidences confirm that young adults are the most susceptible and highrisk group among general population and should be the focus of special attention for preventive and screening programs. No statistically significant differences were observed for subgroup analyses based on climate and outcome of completed suicide.

\section{Conclusions}

The results of this survey identified and highlighted the most common and important potential risk factors for suicide. In addition, the effects of various demographic risk factors on completed suicide were examined. These evidences may be useful for future research, policy, and treatment efforts aimed at understanding and preventing suicide. Hanging was found to be the most common choice of suicide in the Bushehr population and was related to an increase in the overall suicide rate. In addition, limiting access to self-immolation and firearms has been an effective strategy to decrease suicide by these particular methods and it is likely that hanging was substituted for these methods. Therefore, we find the most fruitful approach to reducing overall suicide rates is to determine and manage the main risk factors (unemployment, addiction, mental illness, and others) and to focus on the accessibility of lethal suicide methods such as hanging. Given that the relationship between the availability of suicide methods and the level of suicide is principally mediated by hanging, this suicide method should be the main target for prevention. Due to its high lethality and particular features, such as being performed in private places, interventions must occur at an earlier time. Research into the causes of suicide indicates that a combination of social and personal factors contributes to the emergence of suicidal ideation and future suicide attempts. Health professionals and mental health professionals in particular, should be aware of people's stressful social circumstances and the probable emergence of depressive symptoms, both clearly related to future 
suicide attempts. We know that the implications of this study are only one part of the improvement of an effective prevention strategy for suicide.

\section{References}

1. Evans E, Hawton K, Rodham K. Factors associated with suicidal phenomena in adolescents: a systematic review of population-based studies. Clin Psychol Rev. 2004 Dec;24(8):957-79. PubMed PMID: 15533280. Epub 2004/11/10. Eng.

2. Conwell Y, Van Orden K, Caine ED. Suicide in older adults. Psychiatric Clinics of North America. 2011;34(2):451-68.

3. Shojaei A, Moradi S, Alaeddini F, Khoda-Doost M, Ghadirzadeh MR, Khademi A. The association between completed suicides and season of the year in an Iranian population. Iranian journal of public health. 2013;42(3):293.

4. Poorolajal J, Rostami M, Mahjub H, Esmailnasab N. Completed suicide and associated risk factors: a six-year population based survey. Archives of Iranian Medicine (AIM). 2015;18(1).

5. Malakouti SK, Davoudi F, Khalid S, Asl MA, Khan MM, Alirezaei N, et al. The Epidemiology of Suicide Behaviors among the Countries of the Eastern Mediterranean Region of WHO: a Systematic Review. Acta Medica Iranica. 2015;53(5):257-65.

6. MORADI SE. Evaluation of suicides resulting in death in Iran, comparing with the world rates. 2002.

7. Eskandarieh S, Hajebi A, Saberi-Zafarghandi MB, Vares-Vazirian M, Asadi A. Demographic risk factors of suicide in Savojbolagh City of Tehran Province: 2007-2009. Ethno Med. 2013;7(3):143-8.

8. Kiadaliri AA, Saadat S, Shahnavazi H, Haghparast-Bidgoli H. Overall, gender and social inequalities in suicide mortality in Iran, 2006-2010: a time trend province-level study. BMJ open. 2014;4(8):e005227.

9. Ajdacic-Gross V, Weiss MG, Ring M, Hepp U, Bopp M, Gutzwiller F, et al. Methods of suicide: international suicide patterns derived from the WHO mortality database. Bulletin of the World Health Organization. 2008;86(9):726-32.

10. Värnik A, Kolves K, van der Feltz-Cornelis CM, Marusic A, Oskarsson H, Palmer A, et al. Suicide methods in Europe: a gender-specific analysis of countries participating in the "European Alliance Against Depression". Journal of Epidemiology and Community Health. 2008;62(6):545-51.

11. Värnik A, Kõlves K, Allik J, Arensman E, Aromaa E, Van Audenhove C, et al. Gender issues in suicide rates, trends and methods among youths aged 15-24 in 15 European countries. Journal of affective disorders. 2009;113(3):216-26.

12. Vijayakumar L. Suicide prevention: the urgent need in developing countries. World psychiatry. 2004;3(3):158-9.

13. Sullivan E, Annest JL, Luo F, Simon T, Dahlberg L. Suicide among adults aged 35-64 years-United States, 1999-2010. Center for Disease Control and Prevention, Morbidity and Mortality Weekly Report. 2013.

14. ASTARAKI P, KEIKHAVANDI S, MANSOURIAN M, BASHIRI S, QORBANI M, REZAPOOR A, et al. A Comparative Study of the Causes and Methods of Suicide Lead to Death Referred to Ilam Legal Medicine Center in 2004-2009. 2014. 
15. Amiri B, Pourreza A, Rahimi Foroushani A, Hosseini SM, Poorolajal J. Suicide and associated risk factors in Hamadan Province, West of Iran, in 2008 and 2009. Journal of research in health sciences. 2012;12(2):88-92.

16. Pompili M, Innamorati M, Vichi M, Masocco M, Vanacore N, Lester D, et al. Inequalities and impact of socioeconomic-cultural factors in suicide rates across Italy. Crisis. 2011.

17. Nazarzadeh M, Bidel Z, Ayubi E, Asadollahi K, Carson KV, Sayehmiri K. Determination of the social related factors of suicide in Iran: a systematic review and meta-analysis. BMC public health. 2013;13(1):1.

18. Eskandarieh S, Hajebi A, Saberi-Zafarghandi MB, Vares-Vazirian M, Asadi A. Demographic risk factors of suicide in Savojbolagh City of Tehran Province: 2007-2009. 2013.

19. Organization WH. The world health report 2002: reducing risks, promoting healthy life: World Health Organization; 2002.

20. Razaeian M, Sharifirad G. Case fatality rates of different suicide methods within Ilam province of Iran. Journal of education and health promotion. 2012;1(1):44.

(C) 2017 by the authors; licensee Preprints, Basel, Switzerland. This article is an open access article distributed under the terms and conditions of the Creative Commons by Attribution (CC-BY) license (http://creativecommons.org/licenses/by/4.0/). 